\title{
Two-dimensional finite elements model for boron management in agroforestry sites
}

\author{
Gokmen Tayfur • Kenneth K. Tanji • Alper Baba
}

Received: 1 September 2008 / Accepted: 23 December 2008 / Published online: 30 January 2009

(C) Springer Science + Business Media B.V. 2009

\begin{abstract}
Agroforesty systems, which are recommended as a management option to lower the shallow groundwater level and to reuse saline subsurface drainage waters from the tile-drained croplands in the drainage-impacted areas of Jan Joaquin Valley of California, have resulted in excessive boron buildup in the soil root zone. To assess the efficacy of the long-term impacts of soil boron buildup in agroforesty systems, a mathematical model was developed to simulate non-conservative boron transport. The developed dynamic two-dimensional finite element model simulates water flow and boron transport in saturated-unsaturated soil system, including boron sorption and boron uptake by root-water extraction processes. The simulation of two different observed field data sets by the developed
\end{abstract}

G. Tayfur

Department of Civil Engineering, Izmir Institute of Technology, Urla, Izmir, Turkey

e-mail: gokmentayfur@iyte.edu.tr

K. K. Tanji

Department of Land, Air and Water Resources, University of California, Davis, CA 95616, USA

e-mail: kktanji@ucdavis.edu

A. Baba $(\bowtie)$

Department of Geological Engineering, Canakkale

Onsekiz Mart University, Canakkale, Turkey

e-mail: alperbaba@comu.edu.tr model is satisfactory, with mean absolute error of $1.5 \mathrm{mg} / \mathrm{L}$ and relative error of $6.5 \%$. Application of the model to three different soils shows that boron adsorption is higher in silt loam soil than that in sandy loam and clay loam soils. This result agrees with the laboratory experimental observations. The results of the sensitivity analysis indicate that boron uptake by root-water extraction process influences the boron concentration distribution along the root zone. Also, absorption coefficient and maximum adsorptive capacity of a soil for boron are found to be sensitive parameters.

Keywords Agroforesty - Boron buildup • Numerical model • Boron sorption • Boron uptake

\section{Notation}

The following symbols are used in this paper:

$b \quad$ root effectiveness function

C boron concentration

$C_{\text {irr }}$ boron concentration in irrigation water

$C_{\mathrm{o}} \quad$ initial boron concentration in the solution phase (gram per liter)

$C_{\text {sorp }}$ boron content by boron adsorption and desorption in the soil

$d \quad$ soil increment depth

$D_{x x} \quad$ total diffusion coefficient in the $x$-direction 
$D_{z z} \quad$ total diffusion coefficient in the $z$-direction

$g \quad$ gravitational acceleration

$K_{\text {ad }}$ adsorption equilibrium constant (liter per kilogram)

$K_{\mathrm{d}} \quad$ distribution coefficient

$K_{\mathrm{r}} \quad$ relative hydraulic conductivity

$K_{s i j} \quad$ saturated hydraulic conductivity tensor

$k_{x x} \quad$ saturated hydraulic conductivity tensor in $x$-direction

$k_{z z} \quad$ saturated hydraulic conductivity tensor in $z$-direction

$n$ unit normal vector perpendicular to the boundary surface

$p \quad$ soil-water pressure

$p_{r} \quad$ root-water pressure

$Q \quad$ the sink/source term for the water

$Q_{\text {adc }}$ maximum adsorptive capacity of the soil for boron (milligram per kilogram)

$Q_{\text {r }} \quad$ rate of root-water extraction

$q \quad$ boron in the sorbed phase (milligram per kilogram)

$q_{n} \quad$ flux normal to the boundary

$q_{o} \quad$ initial boron in the sorbed phase (milligram per kilogram)

$q_{x} \quad$ unit flux in $x$-direction

$q_{z} \quad$ unit flux in $z$-direction

$S_{\mathrm{s}} \quad$ storage coefficient

$U_{\mathrm{br}} \quad$ boron uptake by root-water extraction

W soil-water content variable (kilogram per liter)

$Y \quad$ amount of desorbed boron (milligram per kilogram)

$\lambda \quad$ a coefficient $(1=$ saturated flow; $0=$ unsaturated flow)

$\lambda_{\text {ad }}$ absorption coefficient

$\theta \quad$ volumetric water content

$\mu \quad$ kinematic viscosity

$\rho \quad$ fluid density

$\rho_{\mathrm{b}} \quad$ bulk density of the porous media

\section{Introduction}

About 0.30 million ha of irrigated lands in the west side of California's San Joaquin Valley (SJV; Fig. 1) is water-logged and salt-affected, and its shallow ground and subsurface agricultural drainage waters contain elevated concentrations

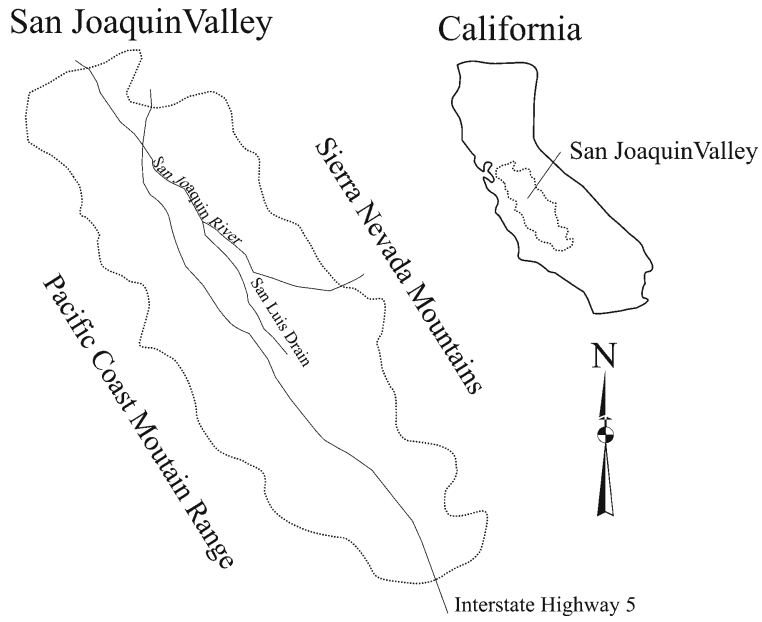

Fig. 1 Map of San Joaquin Valley

of toxic trace elements such as selenium, arsenic, molybdenum, and boron (NRC 1989). Such waters containing high concentrations of toxic elements are known to adversely impact the surface and ground water quality. As a solution to this problem, on-farm water management practices have been recommended to reduce drainwater production (SJVDP 1990). One of the on-farm water management practices is to establish an agroforestry site, which contains salttolerant trees. High saline waters collected from agricultural subsurface drainage can be reused to irrigate these trees. Such a practice also lowers the saline shallow groundwater levels (Tanji and Karajeh 1993).

The long-term efficacy of agroforestry systems to manage saline agricultural drainwaters is under investigation in the west side of San Joaquin Valley by a number of state and federal agencies. As an example, 11.45 ha agroforestry plantation was established at Murrieta farms, south of Mendota in SJV for research purposes. The site contains salt-tolerant Eucalyptus trees and Atriplex shrubs. The details of this site can be obtained from Karajeh (1991). Saline subsurface drainwaters from Murrieta Farm's croplands are used to irrigate the Eucalyptus. The effluents from the Eucalyptus and the perimeter interceptor drain are then used to irrigate the Atriplex. The drainwaters utilized and that available from the tile drainage system are quite saline, EC ranging from about 
6 to $20 \mathrm{dS} / \mathrm{m}$; high in sodicity, sodium adsorption ratio about 10 to 30; and high in boron, about 10 to $40 \mathrm{mg} / \mathrm{L}$ (Westcot et al. 1988; Tanji and Dahlgren 1990; Grattan et al. 1997).

Although salinity is a major concern in the performance of salt-tolerant trees and halophytes in consuming saline drainwaters, there is an increasing evidence of sodicity buildup in the surface soil and boron buildup in the root zone (Tanji and Karajeh 1993). Significant increases in the boron concentration along the soil profile are observed at the agroforestry site at Murrieta farms in Mendota from 1987 to 1990. Accumulation of soil boron may become toxic to plants, even to the salt-tolerant trees.

Boron is a constituent of practically all natural waters, yet its concentration is usually very low. The effect of a concentration of B in the irrigation water on the B content of the soil solution is conditioned by soil characteristics and management practices, which influence the degree of $\mathrm{B}$ accumulation in the soil. B concentration limits are recommended for irrigation waters, although crop tolerance can vary depending on the type of crop and soil. Soils that adsorb B to a higher degree protect the plants by reducing the availability of B in the soil (Webster and Timperley 1995). The approximate safe limit for sensitive crops (for example, grape, pear, orange, lemon) is $0.7 \mathrm{mg} / \mathrm{L} \mathrm{B}$ in the soil saturation extract, 0.7 to $1.5 \mathrm{mg} / \mathrm{L}$ range is marginal, and more than $1.5 \mathrm{mg} / \mathrm{L}$ appears to be unsafe (Camp 1963). Boron contamination is a common problem in the world, including Turkey. For example, Western Anatolia in Turkey has a particularly important role in agriculture. Most of the high temperature thermal water sources and vineyards are also located in this part. Furthermore, part of the irrigation water demand in this area is supplied by drilled wells. All these cause high accumulation of $\mathrm{B}$ concentrations in the soil and groundwater (Lindal and Kristmannsdóttir 1989; Baba and Ármannsson 2006). It has not been possible to use highly B-contaminated areas in this part of Turkey for agricultural purposes.

In order to assess the efficacy of the longterm impacts of soil boron buildup in agroforestry systems, a dynamic two-dimensional finite elements model was employed. The model can simulate two-dimensional saturated-unsaturated water flow and boron transport, including seasonal variations of soil water and boron concentration distribution in irrigated and under-drained agroforestry systems. Boron sorption (adsorption/ desorption) and boron uptake by root-water extraction processes are considered in the transport model. The flow dynamics part of the model was originally developed by Nour el-Din (1986). Then, the model was extended by Karajeh et al. (1994) for modeling salt transport. This study further extended the existing code to include boron sorption and boron uptake by root-water extraction modules to simulate the boron transport in saturatedunsaturated soils.

\section{Mathematical development}

\section{Boron transport model}

The extended model considers boron adsorption/ desorption process, which acts as a source/sink, and boron uptake by root-water extraction process, which acts as a sink for the boron concentration in the solution phase. When the conservation law for solute mass is applied for a representative elementary volume of a porous media, the advection-dispersion equation with sink and source terms for boron transport is expressed as:

$$
\begin{aligned}
\frac{\partial}{\partial t}\left(\theta C+\rho_{\mathrm{b}} K_{\mathrm{d}} C\right)= & \frac{\partial}{\partial x}\left(\theta D_{x x} \frac{\partial C}{\partial x}\right) \\
& +\frac{\partial}{\partial z}\left(\theta D_{z z} \frac{\partial C}{\partial z}\right)-\frac{\partial}{\partial x}\left(q_{x} C\right) \\
& -\frac{\partial}{\partial z}\left(q_{z} C\right) \pm C_{\text {sorp }}+Q C_{\text {irr }} \\
& -U_{\mathrm{br}}
\end{aligned}
$$

where $\rho_{\mathrm{b}}$ is the bulk density of the porous media, $K_{\mathrm{d}}$ is the distribution coefficient, $C$ is the boron concentration, $D_{x x}$ is the total diffusion coefficient (molecular diffusion plus hydrodynamic dispersion) in the $x$-direction, $D_{z z}$ is the total diffusion coefficient (molecular diffusion plus hydrodynamic dispersion) in the $z$-direction, $q_{x}$ is the unit flux in $x$-direction, $q_{z}$ is the unit flux in $z$-direction, $C_{\text {irr }}$ is the boron concentration in irrigation water, $C_{\text {sorp }}$ is the boron content by 
boron adsorption and desorption in the soil, $\theta$ is the volumetric water content, and $U_{\mathrm{br}}$ is the boron uptake by root-water extraction.

Numerical solution of Eq. 1 requires initial and boundary conditions. As an initial condition, zero boron concentration along the soil profile is specified. The boundary conditions can be specified as Dirichlet type, Neuman type, and Cauchy type for specified concentration, zero flux, and prescribed flux, respectively. The details can be obtained from Nour el-Din et al. (1987) and Karajeh et al. (1994). Note that the flow part of the model has been already tested and validated in their studies.

\section{Boron sorption model}

Boron in soils exists partly in the solution and partly in the sorbed phase, and boron fixation in soils may range from temporary to nearly permanent. The more permanently fixed boron is released at a slow rate and at low concentrations. In this study, readily leachable boron, which includes soluble boron and that part of fixed boron which desorbs easily, was considered. For the prediction of adsorption and desorption of boron, the Langmuir adsorption isotherm was considered. The Langmuir adsorption isotherm is commonly employed in the practice for modeling the boron sorption process. For example, Shani et al. (1992) considered a number of sorption models for movement of boron in Utah soils. In their transient solute transport model, they chose to use the Langmuir adsorption isotherm over others because input data for field soils were not readily available for the more sophisticated sorption models. The Langmuir adsorption isotherm equation is expressed as (Tanji 1969):

$q=\left(K_{\mathrm{ad}} Q_{\mathrm{adc}}\right) /\left(1+K_{\mathrm{ad}} C\right)$

where $q$ is the boron in the sorbed phase (milligram per kilogram), $K_{\text {ad }}$ is the adsorption equilibrium constant (liter per kilogram), and $Q_{\text {adc }}$ is the maximum adsorptive capacity of the soil for boron (milligram per kilogram).

Boron concentration in the solution phase and boron in the sorbed phase are computed depending upon their initial values, amount of boron desorbed, and soil-water content variable. This can be expresses as (Tanji 1969):

$$
\begin{aligned}
& C=C_{\mathrm{o}}+W Y \\
& q=q_{\mathrm{o}}-Y
\end{aligned}
$$

where $C_{0}$ is the initial boron concentration in the solution phase (milligram per liter), $q_{\mathrm{o}}$ is the initial boron in the sorbed phase (milligram per kilogram), $W$ is the soil-water content variable (kilogram per liter), and $Y$ is the amount of desorbed boron (milligram per kilogram).

When Eqs. 3 and 4 are substituted into Eq. 2, the following equation is obtained for the computation of the amount of desorbed boron in any soil column:

$Y=q_{\mathrm{o}}-\frac{\left[K_{\mathrm{ad}} Q_{\mathrm{adc}}\left(C_{\mathrm{o}}+W Y\right)\right]}{\left[1+K_{\mathrm{ad}}\left(C_{\mathrm{o}}+W Y\right)\right]}$

Since adsorption and desorption can take place simultaneously at different depths in a soil column, $Y$ has a positive value for desorption and negative value for adsorption. Desorption and adsorption of boron act as source and sink for the boron concentration in the solution phase in a soil column, respectively. In the computation procedure, $Y$ is, first, estimated from Eq. 5 with $K_{\text {ad }}$, $Q_{\text {adc }}$ for that particular element. Then, $C$ and $q$ are computed through Eqs. 3 and 4 by substituting $Y$ into these equations. For the next time step, $C$ and $q$ found from Eqs. 3 and 4 are substituted back into Eq. 5 as $C_{\mathrm{o}}$ and $q_{\mathrm{o}}$, respectively. This procedure is continued for each time step until the end of the simulation period.

Boron uptake model

Boron uptake by root-water extraction can be formulated as analogous to nitrate uptake by plants described by Tanji and Mehran (1979):

$U_{\mathrm{br}}=\lambda_{\mathrm{ad}} C Q_{\mathrm{r}} / \theta$

where $\lambda_{\text {ad }}$ is the root absorption coefficient, which can be set if boron uptake is assumed to be proportional to root-water extraction, $Q_{\mathrm{r}}$ is the rate of root-water extraction, and $\theta$ is the soil-water content.

The rate of root-water extraction $Q_{\mathrm{r}}$ is expressed in many different ways in the literature 
(Nimah and Hanks 1973; Molz and Remson 1970; Gupta et al. 1978; Feddes et al. 1974). In this study, the method of Feddes et al. (1974) is employed and expressed as:

$$
Q_{\mathrm{r}}=K_{\mathrm{r}} K_{s i j}\left(p-p_{\mathrm{r}}\right) b
$$

where $K_{\mathrm{r}}$ is the relative hydraulic conductivity, $K_{s i j}$ is the saturated hydraulic conductivity tensor, $p$ is the soil-water pressure, $p_{\mathrm{r}}$ is the root-water pressure, and $b$ is the root effectiveness function.
In Eq. 7, all the diagonal components of the saturated hydraulic conductivity tensor are implicitly assumed to be zero (Davis and Neuman 1983). The root-water pressure $p_{\mathrm{r}}$ is equal to the soil wilting point pressure head of $-150 \mathrm{~m}$ of water (Davis and Neuman 1983). The root effectiveness term is a shape function which accounts for the physics of the root uptake, and it is evaluated and defined in many different ways in the literature (Gardner 1964; Whisler et al. 1968; Nimah and Hanks 1973;
Fig. 2 Model flow chart for sequence of computations

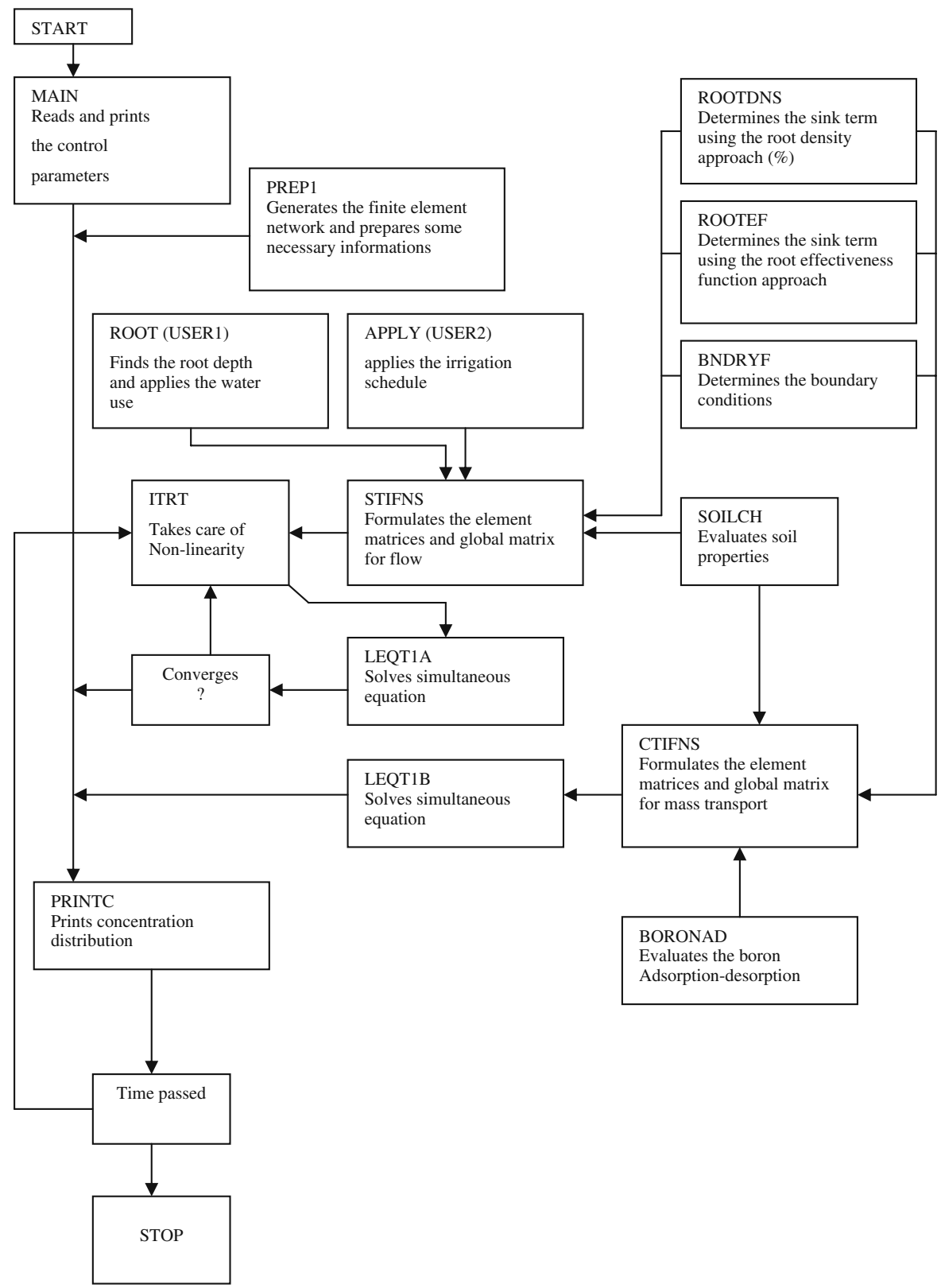


Karajeh et al. 1994). In this study, the formulation of Karajeh et al. (1994) was employed. Karajeh et al. (1994) experimentally evaluated the root effectiveness function for Eucalyptus by taking the ratio between the root lengths in increment in the soil profile to the bulk volume of the root zone per tree. The resulting expression for the root effectiveness function obtained by Karajeh et al. (1994) for Eucalyptus is a third degree polynomial:

$$
\begin{aligned}
b= & 57.41-0.88 \times d+5.32 \mathrm{E}-3 \times d^{2} \\
& -1.15 \mathrm{E}-5 \times d^{3}
\end{aligned}
$$

where $d$ is the soil depth. According to Karajeh et al. (1994), water extraction by roots is higher at the top part of the soil depth. About $40 \%$ of the water extraction occurs at the top $25 \%$ of the root depth, and about $75 \%$ of the water extraction occurs at the top $50 \%$ of the root depth.

Equations describing water flow and boron transport in a soil column (crop root zone) are solved numerically by employing the finite elements method (FEM). The existing FEM code developed by Nour el-Din et al. (1987) was extended in this study by coding and incorporating subroutines related to boron sorption and boron uptake by root-water extraction processes into the main program. Figure 2 shows the flow chart of the developed model. The details of the numerical method can be obtained from Neuman (1973), Davis and Neuman (1983), Nour el-Din (1986), Karajeh (1991), Karajeh et al. (1994), and Yurekliturk (2002).

\section{Model application}

Hypothetical case

The results obtained from the application of the model to a hypothetical case are discussed in this section. The objective of this discussion is to investigate the behavior of boron transport under changing physical conditions. For a hypothetical case, an agroforestry site ( $7 \mathrm{~m}$ in horizontal direction and $3 \mathrm{~m}$ in vertical direction), which contains Eucalyptus is considered. The site is assumed to have drainage at the depth of $210 \mathrm{~cm}$. The
Table 1 Assumed irrigation rates for hypothetical case

\begin{tabular}{llll}
\hline $\begin{array}{l}\text { Time } \\
\text { (day) }\end{array}$ & $\begin{array}{l}\text { Irrigation rate } \\
(\mathrm{cm} / \text { day })\end{array}$ & $\begin{array}{l}\text { Time } \\
\text { (day) }\end{array}$ & $\begin{array}{l}\text { Irrigation rate } \\
(\mathrm{cm} / \text { day })\end{array}$ \\
\hline $0.2-1.2$ & 3.13 & $54.2-55.2$ & 5.33 \\
$10.2-11.2$ & 3.13 & $65.2-66.2$ & 7.96 \\
$21.2-22.2$ & 3.13 & $76.2-77.2$ & 7.96 \\
$32.2-33.2$ & 5.33 & $87.2-88.2$ & 8.04 \\
$43.2-44.2$ & 5.33 & & \\
\hline
\end{tabular}

maximum root depth is assumed to be $210 \mathrm{~cm}$. Irrigation water is applied every 15 days for $24 \mathrm{~h}$. The irrigation water application rate depends on the dynamic soil moisture requirements. The model computes the evapotranspiration rate and resulting soil moisture deficit and then applies the irrigation water rate accordingly. The boron concentration in the applied irrigation water is assumed to be $8.4 \mathrm{mg} / \mathrm{L}$. For this purpose, a small mesh consisting of 96 elements and 121 nodes is prepared. The vertical and horizontal dimensions of the elements are kept small in the vicinity of the drain where large hydraulic gradients are expected to occur. On the other hand, the dimensions of the elements are kept large in the saturated zone where hydraulic gradients are expected to be relatively small. The assumed main physical properties of the soil are as follows: bulk density $\left(\rho_{\mathrm{b}}\right)=1.385 \mathrm{~g} / \mathrm{cm}^{3}$, porosity $=0.425$ and saturated hydraulic conductivity $=13.3 \mathrm{~cm} /$ day. The assumed applied irrigation rates and evaporation rates are given in Tables 1 and 2, respectively.

Effect of simulation time and irrigation application

Figure 3 presents the boron distribution profile at a location $200 \mathrm{~cm}$ from the drain in time. As seen, there is gradual increase in the boron buildup in time. This increase is more pronounced at every 10 days when there is an irrigation application.

Table 2 Assumed evaporation rates for hypothetical case

\begin{tabular}{ll}
\hline Time (day) & Evaporation rate (cm/day) \\
\hline $0-30$ & 0.461 \\
$30-61$ & 0.537 \\
$61-91$ & 0.64 \\
$91-121$ & 0.61 \\
\hline
\end{tabular}


Fig. 3 Boron

concentration profile at $200 \mathrm{~cm}$ from drain in time

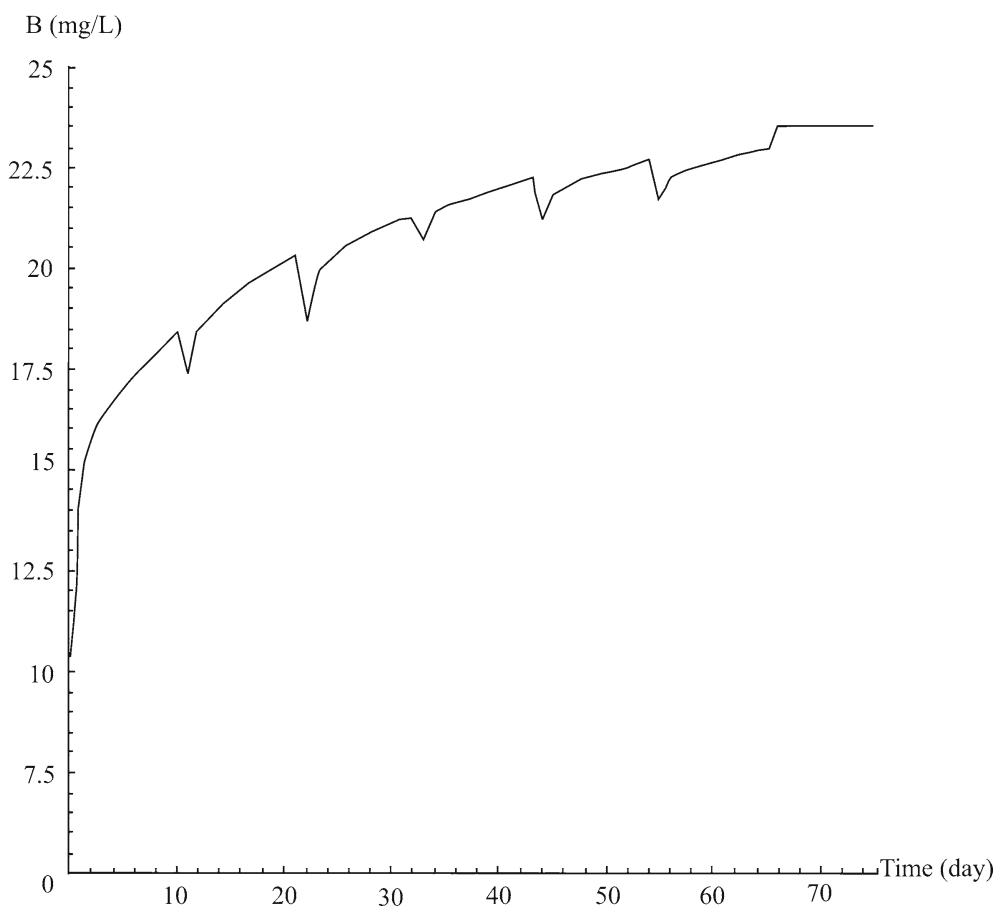

Effect of Langmuir parameters

Figure 4 shows the effect of $K_{\mathrm{ad}}$ on boron profiles at $200 \mathrm{~cm}$ from the drain on the 20th day of the simulation in the soil zone. As seen, an increase in $K_{\mathrm{ad}}$ results in lower concentration distribution in the soil zone, especially in the unsaturated (vadose) zone. Figure 5 shows the effect of $Q_{\text {ad }}$ on the boron concentration profile in the soil zone on the 60th day of the simulation. As seen, an increase in $Q_{\text {ad }}$ results in a decrease in boron concentration in the soil.

Effect of B concentration in irrigation water

Figure 6 shows the effect of $\mathrm{B}$ concentration in applied irrigation water onto the $\mathrm{B}$ concentration
Fig. 4 Effect of $K_{\mathrm{ad}}$ [adsorption equilibrium constant (liter per kilogram)] on boron concentration profile in soil zone

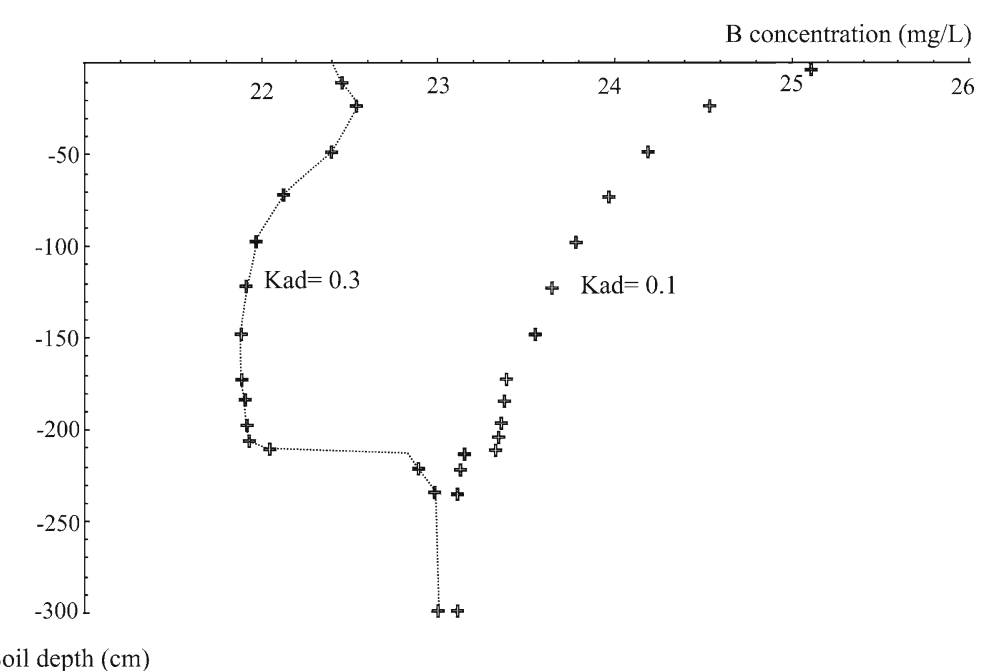


Fig. 5 Effect of $Q_{\text {adc }}$ [maximum adsorptive capacity of soil for boron (milligram per kilogram)] on boron concentration profile in soil zone
Fig. 6 Effect of B concentration in applied irrigation water $\left[C_{\mathrm{irr}}\right]$ on boron concentration distribution in soil zone
Fig. 7 Effect of root absorption coefficient $\left[\lambda_{\mathrm{ad}}\right]$ on $\mathrm{B}$ distribution in soil zone
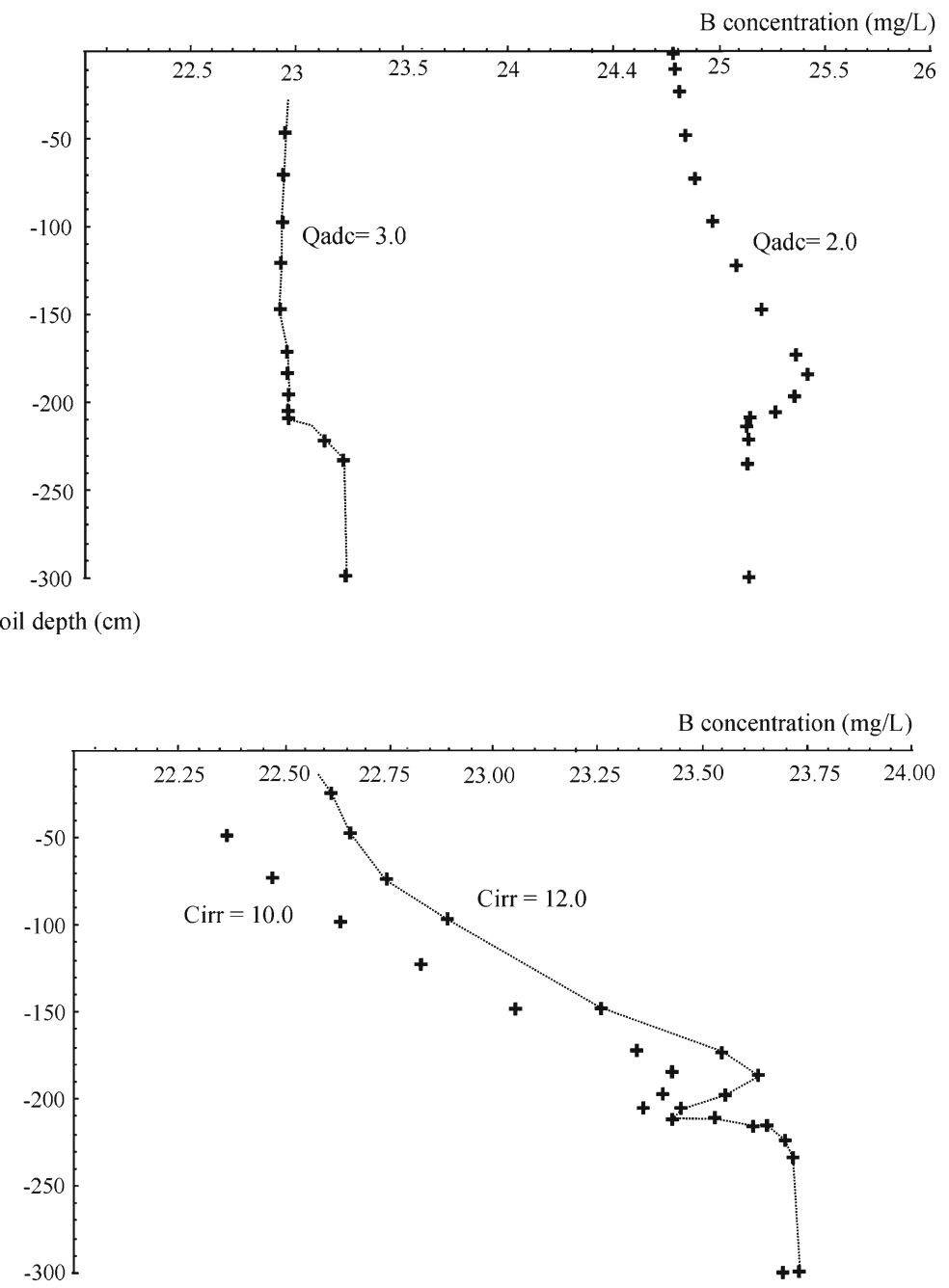

Soil depth (cm)

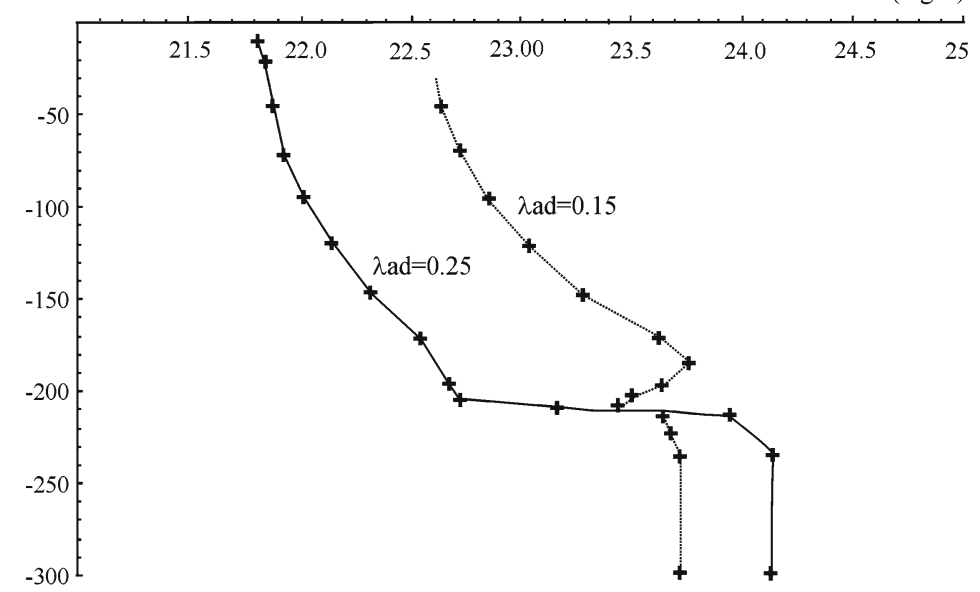

Soil depth $(\mathrm{cm})$ 
Table 3 Langmuir constants

\begin{tabular}{lll}
\hline Soil type & $K_{\mathrm{ad}}(\mathrm{L} / \mathrm{kg})$ & $Q_{\mathrm{adc}}(\mathrm{mg} / \mathrm{kg})$ \\
\hline Soil I & 0.046 & 10.8 \\
Soil II & 0.038 & 20.1 \\
Soil III & 0.088 & 6.7 \\
\hline
\end{tabular}

profile in the soil zone at the 20th day of the simulation period. As seen, an increase in B concentration in applied irrigation water results in an increase in the boron concentration distribution in the soil zone. This is an expected result, and the model is able to capture this behavior.

\section{Effect of root absorption coefficient}

Figure 7 shows the effect of root absorption coefficient on the $\mathrm{B}$ concentration profile in the soil zone. As seen, as the root absorption coefficient increases, the boron concentration decreases. This implies that the increase in the coefficient results in an increase in the plant uptake. This, in turn, reduces the $\mathrm{B}$ concentration in the solution phase along the soil depth.

The hypothetical case studies summarized above show that the model is able to capture the behavior of the B transport in field conditions.

Model application to laboratory experiments

The extended model is applied to investigate the boron concentration behavior in three differ- ent soils-sandy loam, silt loam, and clay loam (Table 3). Table 3 presents the Langmuir constants $K_{\text {ad }}$ and $Q_{\text {adc }}$ for each soil. These values are obtained from Tanji (1969) who performed laboratory studies on boron equilibria in these soils by adding boron as boric acid at rates of 2 to $50 \mathrm{mg} / \mathrm{L}$. He determined the boron in the supernatant of $1: 1$ soil-water suspensions by the carmine method and obtained Langmuir constants $K_{\text {ad }}$ and $Q_{\text {adc }}$ for each soil by the procedure described by Hatcher and Bower (1958). The system that is considered in the hypothetical case is employed in this case as well. The only difference is that of having three different soils with different Langmuir constants.

Figure 8 compares the boron concentration in the solution phase along the soil depth for three different soils. As seen from Fig. 8, boron concentration in the solution phase is lower in silt loam than that in sandy loam and clay loam. This means that boron adsorption is higher in silt loam than that in the other soils. It is also seen in Fig. 8 that, although the boron adsorption is higher in sandy loam than in clay loam, this difference is not large. These results are in agreement with Tanji (1969). As an example, for $10 \mathrm{mg} / \mathrm{L}$ added boron, Tanji (1969) measured $7.5 \mathrm{mg} / \mathrm{L}$ soluble boron in sandy loam, $6.6 \mathrm{mg} / \mathrm{L}$ soluble boron in silt loam, and $7.4 \mathrm{mg} / \mathrm{L}$ soluble boron in clay loam, and for $30 \mathrm{mg} / \mathrm{L}$ added boron, Tanji (1969) measured $24 \mathrm{mg} / \mathrm{L}$ soluble boron in sandy loam, $21 \mathrm{mg} / \mathrm{L}$ soluble boron in silt loam, and $25 \mathrm{mg} / \mathrm{L}$ soluble boron in clay loam.
Fig. 8 FEM model application to three different soils

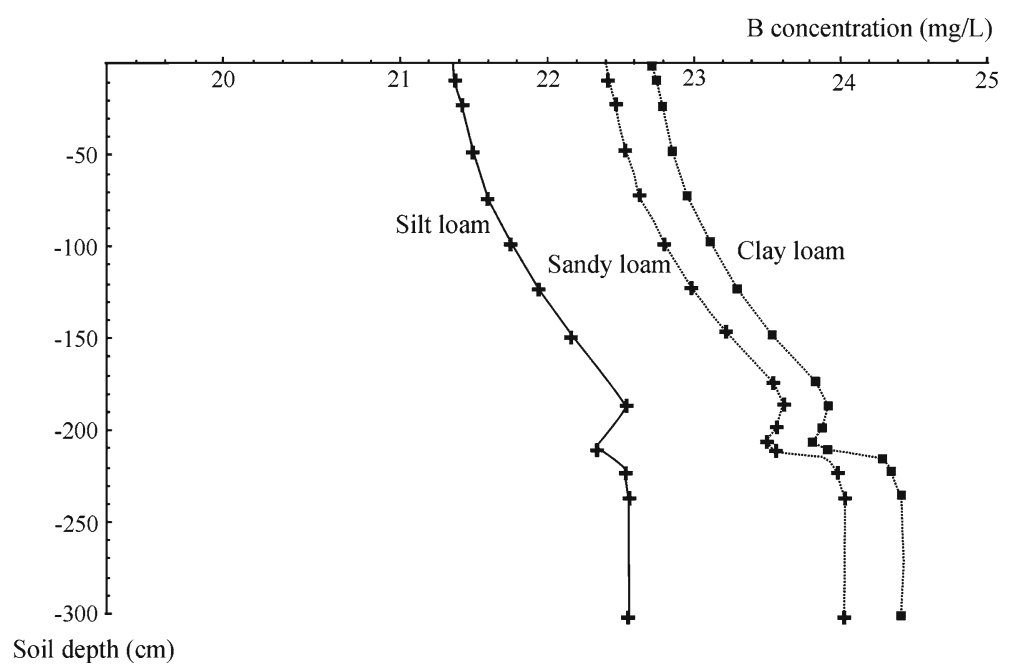


Table 4 Soil characteristics parameters for soil type I [silty clay] and soil type II [clay]

\begin{tabular}{llllllll}
\hline Soil type & $\theta_{\mathrm{r}}$ & $\theta_{\mathrm{S}}$ & $\alpha$ & $n$ & $S_{\mathrm{e}}$ & $K_{\mathrm{s}}(\mathrm{cm} / \mathrm{day})$ & $\rho_{\mathrm{b}}\left(\mathrm{g} / \mathrm{cm}^{3}\right)$ \\
\hline I & 0.02530 & 0.425 & 0.0250 & 1.65 & 0.0002 & 13.3 & 1.385 \\
II & 0.02525 & 0.425 & 0.0129 & 1.98 & 0.0002 & 13.3 & 1.385 \\
\hline
\end{tabular}

$\theta_{\mathrm{s}}, \theta_{\mathrm{r}}$ are the saturated and residual field volumetric water contents, respectively; $K_{\mathrm{s}}$ is the saturated hydraulic conductivity; $n$ and $\alpha$ are statistical parameters to be found by the least-square fitting for the specific soil type using the model of van Genuchten; and $S_{\mathrm{e}}$ is the reduced water content (see Nour el-Din et al. 1987 and Karajeh et al. 1994)

Model application to field data

The extended model is applied to simulate two different data sets obtained from the Mendota site. The first data set belongs to the 1985-1990 plantations, and the second one belongs to the 1992 plantations. The Mendota site is the first monitored agroforestry demonstration project established by NRCS and CDFA. The experimental site consists of fine textured silty clay $(0$ to $60 \mathrm{~cm})$ to clay soils $(60 \mathrm{~cm}$ to $300 \mathrm{~cm}$ ) underlain by an impermeable clay layer at 3 to $3.7 \mathrm{~m}$ depths over the entire plantation. Table 4 shows the soil properties parameters for the two soil layers. Several lines of Eucalyptus camendulensis were planted in 1985 and 1986. The under-drainage system was installed in 1987. The trees were surface irrigated with saline drainage waters collected from croplands about two years after planting. The irrigation was performed from April to November of each year. The total irrigation depths were $370 \mathrm{~mm}$ in 1988, $530 \mathrm{~mm}$ in 1989, and 1,055 mm in 1990. The irrigation rates were applied almost every 10 days for about $24 \mathrm{~h}$. The irrigation application efficiency, which shows the amount of water stored in the crop root zone compared to the amount of irrigation water applied, was
$75 \%$. The average annual crop evapontraspiration depth was about $450 \mathrm{~mm}$. The average boron concentration in the irrigation water was $12 \mathrm{mg} / \mathrm{L}$. The trees performed remarkably well until they suffered killing frost damage in December 1990. Most of the detailed observations were made between the fall of 1987 and the summer of 1990. For model simulation, the finite element mesh with 616 elements and 669 nodes were constructed (Fig. 9). In order to capture the effect of gradients in the solution domain, the number of elements was increased; thereby, the size of elements was kept smaller. Table 5 shows model predictions of measured data at the Mendota site in 1990. Since there were only four observations along the soil depth, we presented results in a tabulated format. As seen in Table 5, the model closely predicted measured data. Following the killing frost of 1990 at the Mendota site and subsequent harvest of the trees, several lines of frost-tolerant Eucalyptus trees were planted in 1992. The experimental site was redesigned, automated for water flows, and the soils were also leached. Table 6 shows that the model predicted measured $\mathrm{B}$ concentration data in 1992. As seen, the model closely captured the measured data. The computed error measures for the results in Tables 5 and 6 are mean absolute
Fig. 9 Finite element mesh with 616 elements and 669 nodes

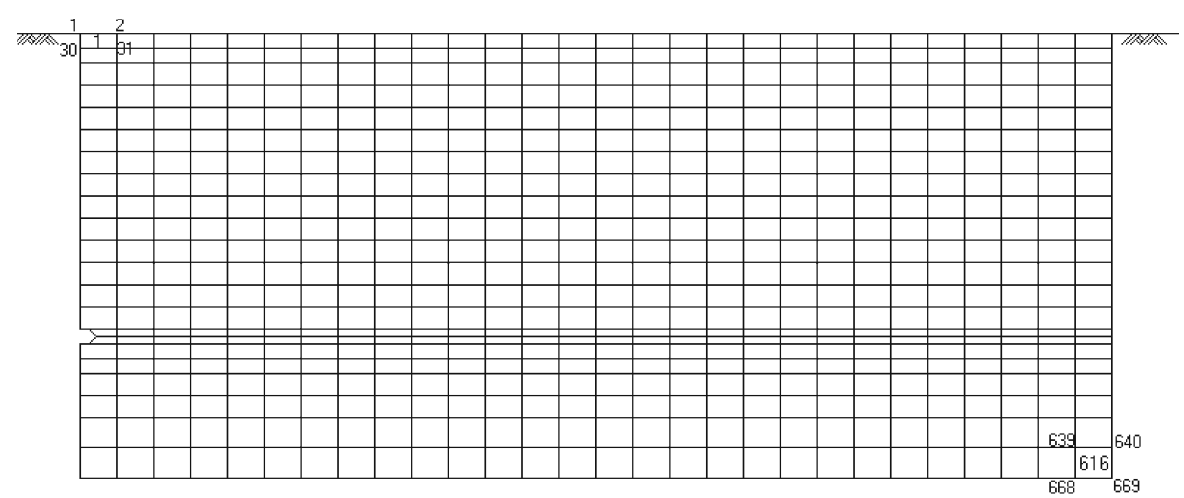


Table 5 FEM model predictions of boron concentrations at Mendota site (1990 observations)

\begin{tabular}{lllll}
\hline Soil depth $(\mathrm{cm})$ & 53 & 110 & 158 & 210 \\
\hline Observed B data $(\mathrm{mg} / \mathrm{L})$ & 17.1 & 22.2 & 25.4 & 30.1 \\
Model predictions $(\mathrm{mg} / \mathrm{L})$ & 19.2 & 23.3 & 26.8 & 28.9 \\
\hline
\end{tabular}

error $=1.5 \mathrm{mg} / \mathrm{L}$ and relative error $=6.5 \%$. These results imply that the model can produce less than $10 \%$ error in predicting measured $\mathrm{B}$ concentration in the soil zone.

\section{Summary and concluding remarks}

In this study, two-dimensional FEM was extended to simulate boron transport in a saturatedunsaturated crop root zone. The model can simulate seasonal variations of soil-water content and boron concentration distribution in irrigated and under-drained agroforestry systems. The model considers boron uptake by root-water extraction and boron adsorption and desorption processes.

Several features of boron transport were investigated by the extended model. The boron uptake by root-water extraction process affects the distribution of the boron concentration profile along the root depth. The boron sorption process also affects the boron transport process. It can be concluded that any modeling approach which ignores any of these physical processes in the boron transport process might lead to misinterpretation of the results. Absorption coefficient $\left(\lambda_{\text {ad }}\right)$ and maximum adsorptive capacity of soil for boron $\left(Q_{\mathrm{adc}}\right)$ were found to be sensitive model parameters. The higher the $\lambda_{\text {ad }}$ is, the greater the decrease in the boron concentration in the solution phase. Similarly, the higher $Q_{\text {adc }}$ and $K_{\text {ad }}$ are, the more boron adsorption occurs. The preliminary indication for the value of $\lambda_{\mathrm{ad}}$ for Eucalyptus was found to be less than 0.10 .

Table 6 FEM model predictions of boron concentrations at Mendota site (1992 observations)

\begin{tabular}{lllll}
\hline Soil depth $(\mathrm{cm})$ & 53 & 110 & 158 & 210 \\
\hline Observed B data $(\mathrm{mg} / \mathrm{L})$ & 18.7 & 25.0 & 24.5 & 32.0 \\
Model predictions $(\mathrm{mg} / \mathrm{L})$ & 19.8 & 24.2 & 27.6 & 30.7 \\
\hline
\end{tabular}

The performance of the extended model was tested by laboratory experimental observations. The application of the model to three different soils having different Langmuir constants showed that adsorption is much higher in silt loam soil than that in sandy loam and clay loam soils. This result agreed with the laboratory experimental observations of Tanji (1969). This implies that the developed model is correctly estimating the effects of the Langmuir constants on the trends of boron concentration in different soils. The successful predictions of measured filed data sets indicate that the developed model can be employed for the management of boron transport in agroforestry sites.

It needs to be pointed out that the extended model requires quite a bit field data such as relative and saturated hydraulic conductivities, relative and saturated soil moisture, porosity, bulk density, diffusion coefficients, the Langmuir constants, etc., for different soils in both the horizontal and vertical directions. In addition, it requires the estimation of van Genuchten infiltration parameters and hydro-meteorological data, which is for the estimation of evapontraspiration. Furthermore, it requires parameter values such as absorption coefficient and root effectiveness function for different trees. As such, for realistic field applications, the model needs to be provided with the required data on soil, flow, and tree properties. It is, however, well known that it is not possible to obtain all the data due to time and budgetary constraints. Instead, representative samples at different locations and different depths can be obtained from the field and subjected to laboratory analysis to provide some of the parameter values. Some parameter values can be complied from the literature, and some can be estimated through statistical methods.

Acknowledgements We thank Emin Yurekliturk for creating the FEM mesh (Fig. 9) and some of the figures (Figs. 1 and 2) and the financial support provided for him by the Izmir Institute of Technology, 2001MUHYL12.

\section{References}

Baba, A., \& Ármannsson, H. (2006). Environmental impact of the utilization of geothermal areas. Energy 
Sources Part B-Economics Planning and Policy, 3(1), 267-278. doi:10.1080/15567240500397943.

Camp, R. T. (1963). Water and its impurities (pp. 136-137). London: Reinhold.

Davis, L. A., \& Neuman, S. P. (1983). Documentation and user's guide: UNSAT2_variable saturated flow model. Rep. NRC FIN B7361, Div. of Waste Mgmt. Office of Nuclear Material Safety and Safeguards. Washington, D.C.: U.S. Nuclear Regulatory Commission.

Feddes, R. A., Bresler, E., \& Neuman, S. P. (1974). Field test of a modified numerical model for water uptake by root systems. Water Resources Research, 10(6), 11991206. doi:10.1029/WR010i006p01199.

Gardner, W. R. (1964). Relation of root distribution to water uptake and availability. Agronomy Journal, 56, $41-45$.

Grattan, S. R., Shannon, M. C., Grieve, C. M., Poss, J. A., Suarez, D., \& Leland, F. (1997). Interactive effects of salinity and boron on the performance and water use of Eucalyptus. ISHS Acta Horticulturae 449: II International Symposium on Irrigation of Horticultural Crops.

Gupta, S. K., Tanji, K. K., Nielsen, D. R., Biggar, J. W., Simmons, C. S., \& MacIntyre, J. L.(1978). Field simulation of soil-water movement with crop water extraction. Water Science and Engineering Paper no. 4013, Dept. of Land, Air and Water Resources, University of California, Davis.

Hatcher, J. T., \& Bower, C. A. (1958). Equilibria and dynamics of boron adsorption by soils. Soil Science, 85 , 319-323. doi:10.1097/00010694-195806000-00005.

Karajeh, F. F. (1991). A numerical model for management of subsurface drainage in agroforestry systems. Ph.D. Dissertation to University of California, Davis, CA.

Karajeh, F. F., Tanji, K. K., \& King, I. P. (1994). Agroforestry drainage management model. I. Theory and validation. Journal of Irrigation and Drainage Engineering, ASCE, 120(2), 363-381.

Lindal, B., \& Kristmannsdóttir, H. (1989). The scaling properties of the effluent water from Kizildere Power Station, Turkey, and recommendation for a pilot plant in view of district heating applications. Geothermics, 18(1/2), 217-223. doi:10.1016/0375-6505(89)90030-8.

Molz, F. J., \& Remson, I. (1970). Extraction-term models of soil moisture use by transpiring plants. $W a$ ter Resources Research, 6, 1346-1356. doi:10.1029/ WR006i005p01346.

NRC, National Research Council (1989). Irrigationinduced water quality problems. What can be learned from the San Joaquin Valley experience. Committee on Irrigation-Induced Water Quality Problems. Washington: National Academy.

Neuman, S. P. (1973). Saturated-unsaturated seepage by finite elements. Journal of Hydraulic Division, ASCE, 99(12), 2233-2250.
Nimah, M. N., \& Hanks, R. J. (1973). Model for estimating soil, water, plant, and atmospheric interrelations: I. Description and sensitivity. Soil Science Society of America Proceedings, 37, 522-527.

Nour el-Din, M. M. (1986). A finite element model for salinity management in irrigated soils. Ph.D. Dissertation to University of California, Davis, CA.

Nour el-Din, M. M., King, I. P., \& Tanji, K. K. (1987). Salinity management model. I. Development. Journal of Irrigation and Drainage Engineering, ASCE, 113(4), 440-453.

SJVDP, San Joaquin Valley Drainage Program (1990). A management plan for agricultural subsurface drainage and related problems on the Westside San Joaquin Valley. Final report by US DOI (BOR, FWS, GS) and California Resources Agency (DWR, F\&G). Sacramento, CA.

Shani, U., Dudley, L. M., \& Hanks, R. J. (1992). Model of boron movement in soils. Soil Science Society of America Journal, 56, 1365-1370.

Tanji, K. K. (1969). A computer analysis on the leaching of boron from stratified soil columns. Soil Science, 110(1), 44-51. doi:10.1097/00010694-197007 000-00008.

Tanji, K. K., \& Mehran, M. (1979). Conceptual and dynamic models for nitrogen in irrigated croplands. In P.F. Pratt (principal investigator), Nitrate in effluents from irrigated lands (p. 555-646). Final Report to the National Science Foundation, University of California, Riverside.

Tanji, K. K., \& Dahlgren, R. (1990). Efficacy of evaporation ponds for disposal of saline drain waters (pp. 1.1-11.16). Final Report to San Joaquin Valley Drainage Program through the Department of Water Resources.

Tanji, K. K., \& Karajeh, F. F. (1993). Saline drainwater reuse in agroforestry systems. Journal of Irrigation and Drainage Engineering, ASCE, 119(1), 170-180.

Webster, J. G., \& Timperley, M. H. (1995). Biological impacts of geothermal development. In Brown, K. L. (convenor), Course on environmental aspects of geothermal development (pp. 97-117). Pre-Congress Courses, Pisa, Italy, 18-20 May 1995.

Westcot, D., Rosenbaum, S., Grewell, B., \& Belden, K. (1988). Water and sediment quality in evaporation basins used for the disposal of agricultural subsurface drainage water in the San Joaquin Valley, California (p. 50). California Regional Water Quality Control Board, Central Valley Region.

Whisler, F. D., Klute, A., \& Millipton, R. J. (1968). Analysis of steady state evapotranspiration from soil columns. Proceedings-Soil Science of America, 32, 167-174.

Yurekliturk, E. (2002). Boron and selenium transport in saturated and unsaturated zones. M.Sc. thesis, Izmir Institute of Technology, Turkey. 